\title{
Procalcitonin as New Proinflammatory Marker in Burn Patients
}

\author{
Amer A. Khaleel', Ruqaya M. Al-Barzinji² \\ ${ }^{1}$ Department of Medical Microbiology, College of Health Sciences, Hawler Medical University, Erbil, Kurdistan Region, Iraq, ${ }^{2}$ Department Basic \\ Sciences, Microbiology Unit, College of Medicine, Hawler Medical University, Erbil, Kurdistan Region, Iraq
}

\author{
*Corresponding author: \\ Amer A. Khaleel, Department \\ of Medical Microbiology, \\ College of Health Sciences, \\ Hawler Medical University, \\ Erbil, Kurdistan Region, Iraq. \\ E-mail: amer.khaleel@hmu. \\ edu.krd
}

\section{Received: 20 June 2020 \\ Accepted: 16 November 2020 \\ Published:30 June 2021 \\ DOI \\ 10.25156/ptj.v11n1y2021.pp58-62}

\section{A B S TR A C T}

Procalcitonin (PCT) is a 116 amino acid peptide with a sequence identical to that of prohormone of calcitonin but devoid of hormonal activity. The aim of this study was to determine PCT and it using as a new prognostic pro-inflammatory marker in burn patients and determine the role of PCT level as a mortality indicator in survival and non-survival burn patients. The burn patients in this study were divided into four groups according to the percentage of total body surface area burned carry out on (50) burn patients admitted to the burn unit in West Erbil Emergency Hospital in Erbil governorate and (20) apparently the healthy non-burn individuals who regarded as healthy control group $(\mathrm{HC})$ in this study from February 2012 to April 2012. Out of 50 burnt patients, 20 patients were second sampled to follow-up their immune profile. Regarding PCT there were significant differences $(P<0.05)$ observed between the mean serum concentration of PCT belong to 18 burn patients of $1^{\text {st }}$ group (G1) $(1.24 \pm 0.82), 23$ patients of $2^{\text {nd }}$ group (G2) (1.52 \pm 0.76$)$, six patients of $3^{\text {rd }}$ group (G3) (2. $\left.16 \pm 0.11\right)$, and three burn patients of $4^{\text {th }}$ group (G4) $(6.5 \pm 2.87)$ with mean serum concentration of $18 \mathrm{HC}(0.02 \pm 0.006)$. Significant differences obtained when compared to $\mathrm{G} 3(2.16 \pm 0.11)$ versus G4 $(6.5 \pm 2.87)$ using the F-test and $t$-test. Results show that PCT is a highly productive laboratory parameter involving an easy and rapid beside test for diagnosis and prognosis mortality in burn patients.

Keywords: Procalcitonin; Total body surface area; Burn patient

\section{INTRODUCTION}

The burn is an injury consisting of the destruction of the skin and the underlying tissues (Siamanga, 2002) It is a significant issue in the world and shows one of the most destructive trauma forms. More than 1,000,000 injuries of burn take place in the United States each year (Enkhbaatar, 2004). Burn can be caused by different agents, for example, heat (scald or flame), chemicals, electricity, freezing, friction, and radiation (Keck et al., 2009).

Various agents affect the mortality and morbidity of injury of burn. First, the burn size, based on the percent of the total body surface area (TBSA) is immediately proportionate to survival. Furthermore, the greater the risk of the systemic infection and sub-sequent burn wounds but the bigger the burn, which is directly related to rise morbidity and mortality (Sheridan, 2000). Second, the injury of inhalation in combination with burns worsens the clinical outcome of the burn patient to the great extent, despite advances in intensive respiratory support (Sterner, 2009). Third, the patient age significantly affects outcomes after burns, as the mortality is higher in old and very young patients in comparison to other groups of age (Pham et al., 2009). It was exhibited time after time in the clinical investigations that mortality was highest in the old patient who had smoke inhalation injury, or/and more severe burns and had finding implicit diseases (McGill et al., 2000).

The injury nature of burn wound is basically resulting of the complex processes causing local, besides systemic complications, affecting multiple organ systems distal to the skin (Evers et al., 2010). The pathogenesis of the progression of the burn wound starts from the original injury site. It includes loss of main tissue owing the denaturation of proteins, which further leads to releasing platelet activating factors and toxic pro-inflammatory assisters into the circulation (Piccolo et al., 1999). Involvement of the immune cell, such as macrophages and neutrophils, resulted in the producing the cytotoxic oxygen free-radical damaging the dermal structure indirectly, or directly (Singh et al., 2007).

Procalcitonin (PCT) is a 116 amino acid peptide with a sequence identical to that of prohormone of calcitonin but devoid of hormonal activity. Since the determination of PCT was first achieved by Assicot et al., 1993 for differentiating between nonbacterial and bacterial causatives of sepsis. One main merit of PCT compared with other parameters is its high and early particular increase in response to sepsis and severe systemic bacterial infections (Müller et al., 2000). Therefore, in the septic conditions 
increased levels of PCT can be noticed 3-6 h after the challenge of infection. Therefore, the main aim of this study is to test PCT as a new prognostic pro-inflammatory marker in burn patients to indicate early and highly specific increases in response to bacterial infections and sepsis.

\section{METHODS}

Fifty burned patients who were admitted to West Erbil Emergency Hospital (WEEH) in Erbil governorate were included in this study from February 2012 to April 2012. Out of 50 burnt patients, 20 patients were second sampled to follow-up their immune profile. The PCT was estimated using (Human PCT ELISA kit) provided by RayBio/USA which is an in vitro enzyme-linked immunosorbent assay for the quantitative measurement of human PCT in serum with a normal range $<0.5 \mathrm{ng} / \mathrm{ml}$ according to the manufacturer's specifications. The calculated TBSA performs by Lund and Browder chart. Blood samples were collected from burned patients, and transferred into $10 \mathrm{ml}$ sterile tube and centrifuged at $3000 \mathrm{rpm}$ for $3 \mathrm{~min}$ and serum was separate from whole blood and stored in deep freeze $\left(-80^{\circ} \mathrm{C}\right)$ in aliquot into several Eppendorf tubes until assayed.

\section{Ethical Consideration}

The present work has been approved from the College of Medicine, Erbil at the research ethics committee of Hawler Medical University. All participants were obtained with written informed consent after procedures and purposes of the study were illustrated.

\section{Experimental design}

The burn patients in this study were divided into four groups: Group 1 (1-25\%), Group 2 (26-50\%), Group 3 (51-75\%), and Group $4(76-100 \%)$ according to the percentage of TBSA \% burned carry out on (50) burn patients admitted to burn unit in WEEH in Erbil governorate and (20) apparently healthy non burn individuals who regarded as a healthy control group (HC). Out of 50 burnt patients, 20 patients were secondly sampled to follow-up their immune profile.

\section{Statistical Analysis}

Statistical analysis has been completed by Statistical Package for Social Sciences ver. 19. The relative proportions have been determined with a confidence interval of $95 \%$. The possible association was identified by Fisher's exact and the Chi-square statistical tests at a probability of $<5 \%$.

\section{RESULTS}

Distribution of burn patients according to gender showed that females represent the majority of burn trauma
$32(64 \%)$ in comparison to male were 18 patients $(36 \%)$ with statistically no significant differences $(P>0.05)$, [Table 1].

On the basis of TBSA \%, burned patients were categorized into four groups (G1, G2, G3, and g4). The highest number of burn injury located in the second group (G2) 23 (46\%), with TBSA $(26-50 \%)$, in which the female was higher than male as shown as in Table 2.

Out of 50 burn patients, 32 females and 18 males, the total number of mortalities was 18 (14 females and 4 males) as shown as in Table 3.

Concerning the survivors and non-survivors burn patients, the number of survivors burn patients in female was $18(56.25 \%)$ and in male was $14(43.75 \%)$ with mean TBSA \% burned (25.23\%) and mean age 20.79. Out of 18 non-survivors burn patient, a large number of burn victim fell in female in which $14(77.78 \%)$, while in male was only $4(22.22 \%)$ with mean TBSA \% burned (52.44\%) and mean age 24.79. Statistical analysis showed that this distribution was no significant difference $(P>0.05)$, [Table 4].

Regarding PCT there were significant differences $(P<$ $0.05)$ observed between the mean serum concentration of PCT belong to 18 burn patients of $1^{\text {st }}$ group (G1) $(1.24 \pm 0.82), 23$ patients of $2^{\text {nd }}$ group (G2) (1.52 \pm 0.76$)$, six patients of $3^{\text {rd }}$ group (G3) $(2.16 \pm 0.11)$, and three burn patients of $4^{\text {th }}$ group (G4) (6.5 \pm 2.87$)$ with mean serum concentration of $18 \mathrm{HC}(0.02 \pm 0.006)$. Significant differences obtained when compared to G3 $(2.16 \pm 0.11)$ versus G4 $(6.5 \pm 2.87)$ using F-test and $t$-test as shown in Tables 5 and 6.

\section{DISCUSSION}

Severe burn injury induces a distinct inflammatory response which is recognized by activation of all inflammatory pathways, dysregulation of cell-mediated immunity, and changes of mediators of the immune system including cytokines, vascular endothelium, growth factors, and different immunocompetent cell populations (Dehne et al., 2002). This study was carried out to investigate the role of PCT and other biological parameters as an inflammatory

Table 1: Gender distribution of burn patients

\begin{tabular}{lcc}
\hline Gender & Burn patients & $\begin{array}{c}\text { Chi-square } \\
P \text { value }\end{array}$ \\
\cline { 2 - 2 } & No. $(\%)$ & 0.14 \\
Female & $32(64)$ & $P>0.05$ \\
Male & $18(36)$ & \\
Total & $50(100)$ & \\
\hline
\end{tabular}

$P>0.05$ : No significant 
Table 2: Burn patients groups according to the TBSA\%

\begin{tabular}{|c|c|c|c|c|c|c|c|c|}
\hline \multirow[t]{2}{*}{ Whole groups } & \multicolumn{2}{|c|}{ Total } & \multicolumn{2}{|c|}{ Male } & \multicolumn{2}{|c|}{ Female } & \multirow[t]{2}{*}{ Age (year)/Mean } & \multirow[t]{2}{*}{ TBSA\%/Mean } \\
\hline & No & $\%$ & No & $\%$ & No & $\%$ & & \\
\hline G1 & 18 & 36 & 9 & 47.06 & 9 & 30.30 & $2.4-44(18.08)$ & $6-25$ (16.67) \\
\hline G2 & 23 & 46 & 7 & 41.18 & 16 & 48.48 & $1.2-39$ (22.49) & $26-50(37.28)$ \\
\hline G3 & 6 & 12 & 1 & 5.88 & 5 & 15.15 & 20-36 (28.17) & $51-75(59.17)$ \\
\hline G4 & 3 & 6 & 1 & 5.88 & 2 & 6.06 & $16-38(26.33)$ & $76-100(86.67)$ \\
\hline Total & 50 & 100 & 18 & 100 & 32 & 100 & $0-50(22.23)$ & $1-86(35.03)$ \\
\hline
\end{tabular}

G1: (6-25\%); G2: (26-50\%); G3: (51-75\%); G4: (76-100\%)

TBSA: Total body surface area

Table 3: Mortality frequency and length of hospitalization of burned patients in both genders in relation to TBSA\%

\begin{tabular}{|c|c|c|c|c|c|c|c|}
\hline \multirow[t]{2}{*}{ TBSA $\%$} & \multicolumn{2}{|c|}{ Gender } & \multirow[t]{2}{*}{ Total } & \multicolumn{2}{|c|}{ Mortality } & \multirow[t]{2}{*}{ Total } & \multirow[t]{2}{*}{ Hospital stay (days) Mean \pm SE } \\
\hline & Female & Male & & Female & Male & & \\
\hline G1 & 9 & 9 & 18 & 1 & 0 & 1 & $8.13 \pm 2.97$ \\
\hline G2 & 16 & 7 & 23 & 8 & 2 & 10 & $7.11 \pm 3.13$ \\
\hline G3 & 5 & 1 & 6 & 3 & 1 & 4 & $5.44 \pm 4.41$ \\
\hline G4 & 2 & 1 & 3 & 2 & 1 & 3 & $2.81 \pm 2.15$ \\
\hline Total & 32 & 18 & 50 & 14 & 4 & 18 & \\
\hline
\end{tabular}

G1: (6-25\%); G2: (26-50\%); G3: (51-75\%); G4: (76-100\%)

Female mortality $14(28 \%)$; Male mortality $4(8 \%)$

Table 4: Distribution of survivor and non-survivor burn patients by gender

\begin{tabular}{lccccc} 
Gender & $\begin{array}{c}\text { Survivors } \\
\text { No.=32 }\end{array}$ & $\begin{array}{c}\text { Non-survivors } \\
\text { No.=18 }\end{array}$ & Chi-square & $P$ value \\
\cline { 2 - 3 } & No. $(\%)$ & & No. $(\%)$ & & \\
\hline Female & $18(56.25)$ & & $14(77.78)$ & 2.97 & 0.08 \\
Male & $14(43.75)$ & & $4(22.22)$ & & \\
Total & $32(100)$ & & $18(100)$ & & \\
\hline
\end{tabular}

P>0.05: no Significant; Total mortality rate: of 18 (36\%)

Table 5: Comparison estimation of mean serum concentration of PCT $(\mathrm{ng} / \mathrm{ml})$ in studied groups according to TBSA\% using ANOVA test

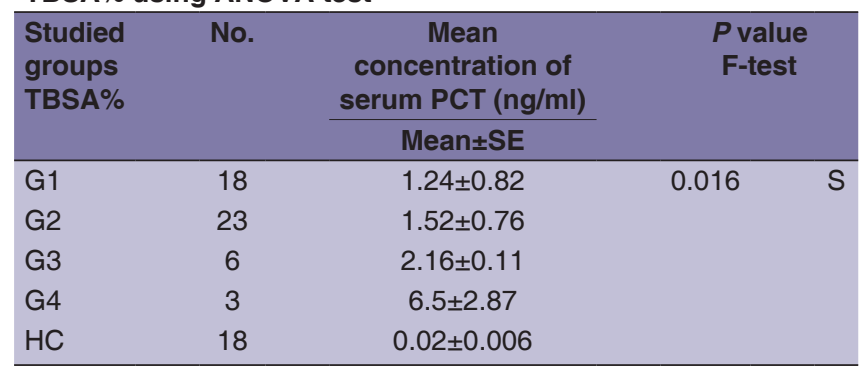

$\mathrm{S}=$ Significant $(P<0.05)$

marker in burned patients. Regarding the distribution of burn trauma in relation to gender, this study showed no significant difference $(P>0.05)$ between male $18(36 \%)$ and female $32(64 \%)$ as shown in Table 1. In agreement with this finding most population-based studies in a developing country have found that the prevalence of thermal injury was higher in women than in men, this concept coincides with a previous study by Hosseini et al., 2007, who found that the most victim of burn injury were females and were caused by suicide attempt through the self-inflicted burn. Sadeghi-Bazargani et al. (2010) also reported that a suicide attempt was common among females. However, the results of the present study were not compatible with those reported by Khan and Malik, 2006, Taghavi et al. (2010) who stated that the incidence of burn trauma among males was more than females. Indeed, the current study showed that females comprised $64 \%$ while male consist of $36 \%$ of admissions in WEEH in Erbil governorate, this high percentage of burn among female is due to family disturbances, which makes a large proportion of female to self-inflicted burn and major reason of marital conflict and improper education level. The highest number 16 of burn patients fell in 20-29 years of the age group, in which $13(40.63 \%)$ in female and $3(16.67 \%)$ in male, the mean age of burn patients was 22.2) years old. The finding of the present study was in agreement with those reported previously by other investigators Othman and Kendrick, 2010, Taghaddosinejad et al., 2010, who showed that the majority of burn patients were younger than 26 years old; they also reported that females were more exposed to burn agents in these age groups than in any other age groups. However, the results in this study contradict those reported by Rooh-ul-Muqim et al., 2007, who stated that children within 1-10 years of age group comprised the largest number of burn patients. The lowest percentage of burn patients, in the current study was fallen in age groups 40-49 years similar finding was reported by Maghsoudi et al., 2005 [Table 7]. Regarding the body extended to burn insult, the current study showed that mean of TBSA $\%$ burned was $(35.03 \%)$ ranged (1-86\%), in which the highest number $23(46 \%)$ of burn victim fell in the $2^{\text {nd }}$ group (G2) $(26-50 \%)$, with mean age (22.49) years old and mean TBSA\% burned (37.28\%), while the lowest number of burn patients located in $4^{\text {th }}$ group (G4) 
$3(6 \%)$ with mean age (26.33) years old and mean TBSA $\%$ burned (86.67\%), eventually another remaining number in current study among burn patients was $6(12 \%)$ and $18(36 \%)$ fell in $3^{\text {rd }}$ group (G3) and $1^{\text {st }}(\mathrm{G} 1)$ group, with mean age and mean TBSA\% were (28.17), (59.17\%), and (18.08), (16.67\%) respectively [Table 2]. Similar finding was reported by several researchers Maghsoudi et al., 2005, and Jeschke et al., 2007, stated that out of 189 burn patients which were distributed into four groups depending on TBSA\% burned, the highest number (79) burn victims fell in the second group with mean TBSA \% (50\%) ranged $(<40->80 \%)$. Throughout this study, the mean TBSA in admitted burnt is $35.03 \%$ ranged $(6-100 \%)$. Although the majority of burn patients $23(46 \%)$ had TBSA burnt $(37.28 \%)$ located in $2^{\text {nd }}$ group, there was a comparatively the small number of patients $3(6 \%)$ with TBSA over $75 \%$, all of whom died contributing to the high mortality in this research, this is mainly due to intentional self-harm burns with fire (flame burns). Out of 50 burn patient admissions, 18 patients died in the hospital giving a mortality rate of $36 \%$. As shown in Table 3, seven of patients with a TBSA burnt over $50 \%$ in which three patients located in the $4^{\text {th }}$ group with TBSA $\%$ (76-100\%) burnt all of them died. The deceased number of burn patients was proportional to TBSA \% burnt as depicted in Table 4. In addition, the length of hospital stay becomes lesser in patients with large burn size. The current study shows that mean length of stay

\begin{tabular}{|c|c|c|}
\hline Studied groups TBSA\% & \multicolumn{2}{|c|}{$P$ value/t-test } \\
\hline $\mathrm{G} 1$ versus $\mathrm{HC}$ & 0.221 & NS \\
\hline $\mathrm{G} 2$ versus $\mathrm{HC}$ & 0.114 & NS \\
\hline $\mathrm{G} 3$ versus $\mathrm{HC}$ & 0.130 & NS \\
\hline G4 versus $\mathrm{HC}$ & 0.001 & HS \\
\hline G1 versus $\mathrm{G} 2$ & 0.777 & NS \\
\hline G1 versus G3 & 0.512 & NS \\
\hline G1 versus G4 & 0.006 & HS \\
\hline G2 versus G3 & 0.636 & NS \\
\hline G2 versus $\mathrm{G} 4$ & 0.008 & HS \\
\hline G3 versus G4 & 0.043 & $\mathrm{~S}$ \\
\hline
\end{tabular}

HS: Highly Significant $(P<0.01)$; S: Significant $(P<0.05)$; NS: Non-significant $(P>0.05)$

Table 7: Distribution of burn patients in both genders in relation to age groups

\begin{tabular}{|c|c|c|c|c|c|c|}
\hline \multirow[t]{3}{*}{ Age group (year) } & \multicolumn{4}{|c|}{ Burn patients No.50 } & \multicolumn{2}{|c|}{ Total } \\
\hline & \multicolumn{2}{|c|}{ Female } & \multicolumn{2}{|c|}{ Male } & & \\
\hline & No. & $\%$ & No. & $\%$ & No. & $\%$ \\
\hline $1-9$ & 3 & 9.37 & 3 & 16.67 & 6 & 12 \\
\hline $10-19$ & 8 & 25 & 7 & 38.89 & 15 & 30 \\
\hline $20-29$ & 13 & 40.63 & 3 & 16.67 & 16 & 32 \\
\hline 30-39 & 6 & 18.75 & 4 & 22.22 & 10 & 20 \\
\hline $40-49$ & 2 & 6.25 & 1 & 5.55 & 3 & 6 \\
\hline Total & 32 & 100 & 18 & 100 & 50 & 100 \\
\hline
\end{tabular}

in various burn groups G1, G2, G3, and G4 was (8.13 \pm $2.97),(7.11 \pm 3.13),(5.44 \pm 4.41)$, and $(2.81 \pm 2.15)$ days, respectively. Most studies from the EMR have reported that mean hospital stay was longer than this ranging from 11 to 16 days as reported by Maghsoudi et al., 2005, Jeschke et al., 2007. The reasons for the shorter hospital stay in this research may be due to higher rates of the mortality and inclusion of the larger number of self-harm burns than in other researches. As shown in Table 5, the highest frequent cause of burn was flame at age group (20-29) years, which denoted as the commonest age group. Finding of a recent study likewise revealed that scald burn comprised as s second commonest cause of the burn, followed by electrical and contact with hot object as an eventual cause of the burn. Similar results were reported by Hemeda et al., 2003, Carlos Siviero do Vale, 2005 who reported that flame was the most frequent cause of the burn.

\section{CONCLUSION}

PCT is a highly efficient laboratory parameter involving a simple and rapid beside test for diagnosis and prognosis mortality in burn patients. The mean concentration of serum PCT shows significant differences when compared independently in deceased and survivor burn patients with HC.

\section{CONFLICTS OF INTEREST}

The author reports no conflicts of interest.

\section{REFERENCES}

Assicot, M., D. Gendrel, H. Carsin, J. Raymond, J. Guilbaud and C. Bohuon. 1993. High serum procalcitonin concentrations in patients with sepsis and infection. Lancet. 341: 515-518.

Dehne, M. G. A. Sablotzki, A. Hoffmann, J. Muhling, F. E. Dietrich and G. Hempelmann. 2002. Alteration of acute phase reaction and cytokine production in patients following severe burn injury. Burn. 28: 535-542.

do Vale, E. C. S. 2005. Initial management of burn. An. Bras. Dermatol. 80(1): 3918.

Enkhbaatar, P. 2004. Pathophysiology of acute lung injury in combined burn and smoke inhalation injury. Clin. Sci. 107(2): 137-143.

Evers, L. H., D. Bhavsar and P. Mailander. 2010. The biology of burn injury. Exp. Dermatol. 19: 777-783.

Hemeda, M., A. Maher and A. Mabrouk. 2003. Epidemiology of burns admitted to Ain Shams University Burns Unit, Cairo, Egypt. Burns. 29(4): 353-358.

Hosseini, R.S., M. Askarian and O. Assadian. 2007. Epidemiology of hospitalized female burn patients in burn center in Sheraz. Eastern Mediterr. Health J. 13(1): 113-118.

Jeschke, M. G., R. P. Mlcak, C. C. Finnerty, W. B. Norbury, G. G. Gauglitz, G. A. Kulp and D. N. Herndon. 2007. Burn size determines the inflammatory and hypermetabolic response. Crit. 
Care. 11(4): R90.

Keck, M., D. H. Herndon, L. P. Kamolz, M. Frey and M. G. Jeschke. 2009. Pathophysiology of burns. Wiener Med. Wochenschr. 159: 327-336

Khan, N. and M. A. Malik. 2006. Presentation of burn injuries and their management outcome. J. Pak. Med. Assoc. 56(9): 394-397.

Maghsoudi, H., A. Garadagi, G. A. Jafary, G. Azarmir, N. Aali, B. Karimian and M. Tabrizi. 2005. Women victims of self-inflicted burns in Tabriz, Iran. Burns. 30: 217-220.

McGill, V., A. Kowal-Vern and R. L. Gamelli. 2000. Outcome for older burn patients. Arch. Surg. 135(3): 320-325.

Müller, B., K. L. Becker, H. Schächinger, P. R. Rickenbacher, P. R. Huber, W. Zimmerli and R. Ritz. 2000. Calcitonin precursors are reliable markers of sepsis in a medical intensive care unit. Crit. Care Med. 28(4): 977-983.

Othman, S. and D. Kendrick. 2010. Epidemiology of burn injuries in the East Mediterranean Region: A systematic review. BMC Public Health. 10: 83.

Pham, T. N., C. B. Kramer, J. Wang, F. P. Rivara, D. M. Heimbach, N. S. Gibran. et al. 2009. Epidemiology and outcomes of older adults with burn injury: An analysis of the national burn repository. J. Burn Care Res. 30: 30-36.

Piccolo, M. T., Y. Wang, P. Sannomiya, N. S. Piccolo, M. S. Piccolo, T. E. Hugli, P. A. Ward and G. O. Till. 1999.
Chemotactic mediator requirements in lung injury following skin burns in rats. Exp. Mol. Pathol. 66: 220-226.

Sadeghi-Bazargani, H., R. Mohammadi, L. Svanstrom, R. Ekman, S. Arshi, S. Hekmat, N. Malekpour and M. Mashoufi. 2010. Epidemiology of minor and moderate burns in rural Ardabil, Iran. Burns. 36(6): 933-937.

Sheridan, R. L. 2000. Evaluating and managing burn wounds. Dermatol. Nurs. 12(1): 17-18.

Siamanga, H. 2002. Burn injuries treatment of burn patients prior to admission to the emergency department. Ann. Burns Fire Disasters. 15(2): 53-58.

Singh, V., L. Devgan, S. Bhat and S. M. Milner. 2007. The pathogenesis of burn wound conversion. Ann. Plast. Surg. 59: 109-115.

Sterner, J. B. 2009. Inflammatory mediators in smoke inhalation injury. Inflamm. Allergy Drug Target. 8: 63-69.

Taghaddosinejad, F., A. Sheikhazadi, B. Behnoush, J. Reshadati and S. H. Sabery. 2010. A survey of suicide by burning in Tehran, Iran. Acta Med. Iran. 48(4): 266-272.

Taghavi, M., M. R. Rasouli, N. Boddouhi, M. R. Zarei, A. Khaji and M. Abdollahi. 2010. Epidemiology of outpatient burns in Tehran: An analysis of 4813 cases. Burns. 36(1): 109-113.

ul-Muqim, R., Z. Mohammad, Dilbag, H. Muhammad and M. I. Khan. 2007. Epidemiology and outcome of burns at Khyber teaching hospital Peshawar. Pak. J. Med. Sci. 23(3): 420-424. 